\title{
(2) PRDDUCுनि口 DNLINE

\section{O ESTILO DE TRABALHAR EM GRUPO E SUA INFLUÊNCIA NO DESEMPENHO DA EQUIPE}

\section{THE STYLE OF GROUP WORKING AND ITS INFLUENCE ON TEAM PERFORMANCE}

\author{
Robson Luiz Montanari E-mail: prof robson@terra.com.br \\ Luiz Alberto Pilatti* E-mail: lapilatti@utfpr.edu.br \\ *Universidade Tecnológica Federal do Paraná (UTFPR), Ponta Grossa, PR
}

Resumo: O presente estudo de caso buscou avaliar a influência da metodologia de trabalho em grupo no desempenho das equipes de uma empresa de médio porte com atividades voltadas à prestação de serviços no Estado do Paraná. Inicialmente foi realizada uma entrevista exploratória. $\mathrm{Na}$ sequência foram aplicados os questionários: Estilo de Trabalhar em Grupo, proposto por Parker (1994) e Avaliação de uma Equipe de Sucesso, proposto por Chang (1999). Juntamente com a aplicação dos questionários, foram feitas observações não participantes que buscaram registrar elementos de interesse aos objetivos da pesquisa. Para finalizar, realizou-se a análise dos dados, através da triangulação com as entrevistas e as observações não participantes. Os resultados identificaram algumas influências da metodologia de trabalho em grupo no desempenho das equipes. Os diferentes comportamentos determinaram o grau de influência contribuindo ou não no desempenho das equipes em estudo. Duas matrizes de resultados foram encontradas: a primeira com uma distribuição relativamente uniforme dos estilos, mas com menor desempenho; a segunda com predominância no estilo contribuinte e um maior desempenho das equipes.

Palavras-chave: Equipes. Estilos de Trabalho em Grupo. Desempenho de Equipes.

Abstract: This case study aims to evaluate the influence of the style of group working in the teams' performance in a midsize services company in Parana State. For this purpose an exploratory interview was originally performed. Then the questionnaires were applied: Working Group Style, proposed by Parker (1994) and Evaluation of a Success Team, proposed by Chang (1999). Besides the questionnaires, non-participant observations were made that intended to register items which interest the research objectives. Finally, the data analysis was carried out, making intersection with the interviews and the non-participant observations. The results identified some influences of the group working styles in the performance of teams. The different behaviors determined the degree of influence which help or not the performance of teams in this study. Two result matrices were found. The first with a relatively uniform distribution of styles, but presenting lower performance; the second showed a predominant contributor style and a higher performance of teams.

Keywords: Teams. Styles of Group Working. Teams Performance.

\section{INTRODUÇÃO}

Em decorrência da necessidade de respostas rápidas às mudanças atuais, os recursos humanos tiveram seus papéis redesenhados dentro de um cenário 
absolutamente novo. Tem se tornado uma constante a adoção da gestão baseada em equipes, ao invés da gestão do trabalho baseado em funções e departamentos.

De acordo com alguns autores como Robbins e Finley (1997), as equipes apresentam vantagens inquestionáveis: melhoram a comunicação; fazem melhor uso dos recursos: são mais criativas na resolução de problemas; criam melhores produtos e serviços e apresentam maior qualidade nos processos de participação e produção. Contudo, para outros autores como Moscovici (2003) e Drucker (2001), a formação de equipes não passa de um clichê nas empresas, pois consideram que equipes reais ainda são raras.

Na visão de Claver-Cortés et al. (2007), as empresas estão buscando nas estruturas mais flexíveis subsídios para superar as adversidades diárias e gerar novos conhecimentos. Para Sacomano e Escrivão Filho (2000), a abertura dos mercados para a concorrência internacional exigiu das empresas esforços significativos para atingir patamares competitivos. Assim, Bejarano (2006a) destaca que a busca constante e incessante por melhorias na performance organizacional é uma realidade nos ambientes de trabalho, pois as organizações são atualmente movidas pela competitividade da economia globalizada e pela necessidade de aumento de produtividade.

Em relação à produtividade, complementa Bejarano (2006a), que as empresas estão buscando cada vez mais investir no trabalho em equipes como parte da sua estrutura organizacional. Peter Drucker (2001) constata e destaca que o trabalho em equipe não é bom nem desejável, é um fato. Sempre que as pessoas trabalham ou jogam em grupos, o fazem em equipe. Outros autores como Chang (1999), Katzenbach e Smith (2001) relatam que as equipes são fundamentais para o desempenho empresarial e podem ser utilizadas como resposta às mudanças organizacionais. Bejarano et al. (2006b), destaca as equipes como fundamentais no atual e moderno ambiente empresarial e menciona ainda, as equipes virtuais como uma ferramenta para auxiliar o trabalho de pessoas dispersas "no espaço e no tempo".

Não obstante, conduzir equipes na obtenção de melhor desempenho não é tarefa fácil, mesmo quando, se podem reunir os melhores talentos individuais. Costa (2003), que em seu estudo discute a importância da confiança na eficácia da equipe, aponta que o ciclo de vida das equipes e o grau de familiaridade entre os membros 
das mesmas são variáveis fundamentais para maximizar o desempenho delas. Moscovici (2003) evidencia dificuldades e questionamentos em relação a esse fato: como fazer as pessoas gostarem umas das outras? Como gerar sentimentos positivos de simpatia e carinho conducentes à cooperação e ao trabalho produtivo em equipe? São indagações importantes, já que a complexidade do comportamento humano está intimamente associada ao desempenho organizacional, que por sua vez, busca nas equipes potencializar os resultados empresariais.

A necessidade de um entendimento mais abrangente do comportamento humano no trabalho em grupo e no desempenho das equipes no ambiente produtivo é, diante da crescente utilização da gestão baseada em equipes, fundamental para formação e reestruturação de equipes nos ambientes de produção. Esses, cada vez mais, necessitam melhorar o desempenho produtivo até mesmo em detrimento da performance empresarial. Assim, o presente artigo tem como objetivo avaliar a influência da metodologia do trabalho em grupo no desempenho das equipes observando e aplicando questionários a sete equipes de uma empresa de médio porte, prestadora de serviços.

\section{METODOLOGIA DE TRABALHO EM GRUPO}

Apesar da abundância de pesquisas sobre as equipes e seus benefícios para as organizações, autores como - Bejarano e Pilatti (2008) e Gilley et al. (2010) enfatizam que as literaturas comerciais influenciam as empresas a desenvolverem o trabalho em equipe. Na prática, porém, observa-se que pouco se sabe sobre como implantar ou utilizar equipes na obtenção do máximo desempenho conjunto. A crença praticamente universal dos executivos na existência de apenas um tipo de equipe é uma ideia equivocada, e que talvez seja justamente a maior razão para o fracasso da formação de equipes. Essa constatação foi feita por Drucker (2001). Para o autor, existem três tipos de equipes verdadeiras, "cada uma diferente em sua estrutura, no comportamento que exige de seus membros, nas suas forças, vulnerabilidade, limitações e exigências, mas acima de tudo naquilo que pode fazer e que deve ser usada" (DRUCKER, 2001, p. 59).

Drucker (2001) distingue os três tipos, considerando que as equipes se diferem no comportamento entre o que fazem melhor e no que não podem fazer: a) 
os membros têm posições fixas e atuam na equipe, mas não em equipe, como uma equipe de beisebol ou uma linha de montagem; b) os membros têm posições fixas, mas atuam em equipe como em uma equipe de futebol; c) os membros têm posições principais ao invés de fixas e devem "cobrir" seus companheiros de equipe, ajustando-se quando necessário, como as duplas de tênis ou um conjunto de jazz.

Uma visão diferente é compartilhada por Fisher et al. (1997), Katzenbach (1999), Salomão (1999), Sacomano Neto e Escrivão Filho (2000) e Moscovici (2003) que relacionam o trabalho em equipe a objetivos comuns, ao compartilhamento de competências e de esforços. O fato de trabalharem em conjunto não dá aos grupos, independente das posições que seus membros ocupem (fixas ou não), o status de "equipe", contrariando o idear de Drucker (2001).

O raciocínio de Drucker (2001) proporciona o entendimento de uma situação que nem sempre é suficientemente clara, pois nem todos os grupos têm a mesma finalidade. Em linhas gerais, não existem justificativas para uma equipe de futebol "jogar" como uma dupla de tênis. Na primeira equipe existe a necessidade de trabalho interdependente, em que os "jogadores" dependem uns dos outros, enquanto na segunda, não. E também não existe justificativas para uma equipe de beisebol "jogar" como uma equipe de futebol, pois na primeira equipe o trabalho é na equipe e não em equipe.

Independente da conformação laboral, adotar ou não o formato de equipes, o trabalho coletivo está intimamente associado ao comportamento humano no trabalho. Na visão de Bejarano et al., (2005a), o comportamento humano é quase sempre involuntário e o comprometimento necessário pode estar ausente. Robbins e Finley (1997, p. 57) compartilham desse pensamento e inferem que as pessoas em equipe são "como as pessoas em qualquer outro lugar", ou seja, "têm seus altos e baixos".

Karakowsky et al. (2004) destacaram percepções e influências no comportamento diferente entre homens e mulheres trabalhando em equipes. $O$ impacto estende-se, além do comportamento e dos sentimentos, às percepções a respeito dos esforços da equipe. Os integrantes podem alterar suas percepções baseando-se, por exemplo, na qualidade de esforços observada nela. Para Solansky (2011), as equipes formadas por membros com alta identificação com a equipe conseguem melhores níveis de perfomance. Os resultados evidenciados pela autora 
mostram que membros que se identificam com a equipe podem desempenhar tarefas mais complexas, entregando resultados mais qualificados.

Montanari (2008), que abordou diferentes comportamentos organizacionais embasados em modelos de comportamento, apresenta uma matriz de resultados onde as equipes com predominância de um comportamento, entre os membros de um grupo, apresentam um grau de maturidade maior, refletindo positivamente no desempenho da equipe. Uma matriz de resultados divergentes é apresentada por Higgs (2005), que enfatiza uma relação bastante clara entre a composição da equipe - a diversidade dos comportamentos ou perfis existentes - e a complexidade da tarefa realizada. Os resultados apresentados pelo autor apontam que a diversidade entre os membros de uma equipe influenciam positivamente na performance da equipe para realização de tarefas complexas.

Para Hersey e Blanchard (1986) o comportamento humano está associado ao perfil das pessoas que compõem uma equipe. Os autores associam o comportamento no trabalho à maturidade do indivíduo para assumir diferentes níveis de capacidade e disposição. "A maturidade é a capacidade e a disposição das pessoas de assumir a responsabilidade de dirigir seu próprio comportamento [...]" (HERSEY e BLANCHARD 1986, p. 187). Em linhas gerais, o indivíduo com maturidade alta tem um estilo de trabalho que pode torná-lo apto a assumir responsabilidades em função da sua capacidade de dirigir seu próprio comportamento. Esse comportamento já não ocorre com as pessoas que apresentam maturidade baixa.

Não obstante, um fator interessante e que merece atenção é o estilo de trabalho que cada pessoa pode apresentar no ambiente produtivo. Uma das técnicas na escolha de pessoas para compor uma equipe é, na visão de Aleixo (2003), é fazer um balanceamento entre os membros que já possuem algumas habilidades com os que não as possuem ou precisam desenvolvê-las.

Armstrong (1997) e Bejarano et al. (2005b) vão além e citam a necessidade de selecionar melhor os membros para as equipes através de, respectivamente, centros de avaliação especializados e de métodos que permitam identificar os perfis. Bejarano et al. (2005b) e Davies e Kanaki (2006), que discutiram o modelo proposto por Meredith Belbin para construção de equipes, mencionam que as organizações podem melhorar o funcionamento de suas equipes identificando os perfis de seus 
membros. Através da análise das características interpessoais, pode-se combinar e equilibrar personalidades para melhorar a performance da equipe. Para Parker (1994), quando as pessoas trabalham em grupo, elas podem ser classificadas em quatro estilos: contribuinte, colaborador, comunicador e desafiador.

O contribuinte é um participante orientado para a execução de tarefas, aprecia fornecer ao grupo informações de boa qualidade e insiste com o grupo para elevar seu desempenho. A maioria das pessoas enxerga-o como alguém em quem se pode confiar. Eventualmente se envolve demasiadamente com os detalhes e não consegue enxergar o todo. As pessoas descrevem o contribuinte como alguém responsável, autoritário, confiável, competente e organizado.

O colaborador é um participante orientado para o objetivo, pois dá maior importância para as metas e missões. A maioria das pessoas vê o colaborador como alguém que consegue enxergar o todo, mas que, às vezes, deixa de dar atenção às tarefas básicas do grupo. As pessoas descrevem o colaborador como alguém que enxerga em longo prazo, orientado para os objetivos, conciliador, flexível e imaginoso.

O comunicador é um participante orientado para o processo, capaz de ouvir bem e de facilitar a participação alheia, a resolução de conflitos, o consenso, o feedback e o desenvolvimento de uma atmosfera descontraída. A maioria das pessoas vê o comunicador como uma pessoa orientada a pessoas. O comunicador é considerado como alguém que não gosta de confronto e é descrito como aquele que apóia e tem consideração pelos outros. É descontraído, entusiasmado e cuidadoso nas relações pessoais.

O desafiador é um participante que questiona os objetivos, métodos e mesmo a ética do grupo. Tem predisposição para discordar do líder e incentiva o grupo a assumir riscos bem calculados. A maioria das pessoas aprecia o valor de sua franqueza e de sua mente aberta. Às vezes, o desafiador fica autoconfiante e pressiona demais os companheiros. Ele é descrito como alguém honesto, que gosta de falar diretamente, tem princípios, é ético e aventureiro.

Uma pessoa pode ter diferentes estilos de trabalho, porém um ou dois deles acabam prevalecendo na maioria do tempo. O estilo principal define um conjunto de comportamentos que será usado mais frequentemente pelo participante de um grupo (PARKER, 1994). Assim como em uma equipe de futebol formada por atletas 
desempenhando papéis diferentes, todos os estilos, na visão de Parker (1994), são necessários para uma equipe, pois todos têm características que são úteis ao bom andamento dos trabalhos em um determinado momento.

Thomaz e Kovaleski (2006, p. 180) utilizando a classificação de estilos de Parker (1994), consideram, "que os estilos "contribuinte e comunicador" são os melhores para que ocorra o compartilhamento do conhecimento tácito [...]". Também Montanari e Pilatti (2009), assim mesmo utilizando a classificação de Parker (1994), concluíram que o estilo contribuinte é um dos mais propícios e o desafiador um dos menos favoráveis para o compartilhamento e criação do conhecimento tácito.

Szezerbicki et al. (2006), apontam que o ambiente de trabalho de uma equipe de alta performance só torna-se desejável quando seus membros reconhecem a necessidade de comprometimento e buscam por resultados coletivos através da soma das capacidades individuais. Embora todos os estilos ou comportamentos tenham sua importância, alguns contribuem de maneira mais significativa para certas atividades no ambiente produtivo. Bejarano (2005b) e Armstrong (1997) - que defendem a ideia de processos de seleção mais consistentes - relacionam este fator como sendo fundamental ao desempenho das equipes. Para Katzenbach (1999, p. 57), "a essência do desempenho de uma equipe se resume a pessoas com habilidades diferentes que trabalham juntas numa mesma tarefa" para alcançar um produto de valor coletivo.

A análise dos estilos de trabalho, coletivamente, pode auxiliar as organizações no sentido de formar grupos ou equipes para atividades específicas ou para conseguir o equilíbrio ideal dos estilos, com comportamentos conducentes e habilidades que viabilizem a maximização do desempenho individual, coletivo e da organização.

\section{O DESEMPENHO DAS EQUIPES}

As equipes podem representar um fator fundamental na busca de vantagens competitivas, pois os "esforços individuais resultam em um desempenho, que é maior que a soma das contribuições de cada um dos indivíduos" (ROBBINS 2001, p. 262). A sinergia, alcançada pela interação das habilidades dos integrantes do grupo, proporciona à equipe condições favoráveis (compromisso com o desempenho, 
compromisso com os objetivos da equipe e responsabilidades mútuas) para potencializar a performance.

O desempenho das equipes no ambiente produtivo é permeado por fatores internos e externos no trabalho coletivo. Bejarano (2006a) delimitou fatores externos que dificultam o trabalho em equipe, relacionando-os a três elementos propostos como essenciais na implementação de equipes: estrutura, estratégia e seleção. A estrutura afeta a cultura e os modelos de gestão organizacionais, a estratégia reflete-se em práticas de desenvolvimento de equipes e a seleção relaciona-se à necessidade de encontrar as pessoas adequadas para formar equipes. Chang (1999) e Bejarano et al. (2005b) apresentam fatores internos - esclarecer funções e responsabilidades, solucionar discordâncias, tomar decisões objetivos - e que também dificultam o desempenho das equipes.

Schwartz (2007) associa o desempenho das pessoas a quatro estados da energia, como mostra a Figura abaixo:

Figura 1 - Matriz de energia

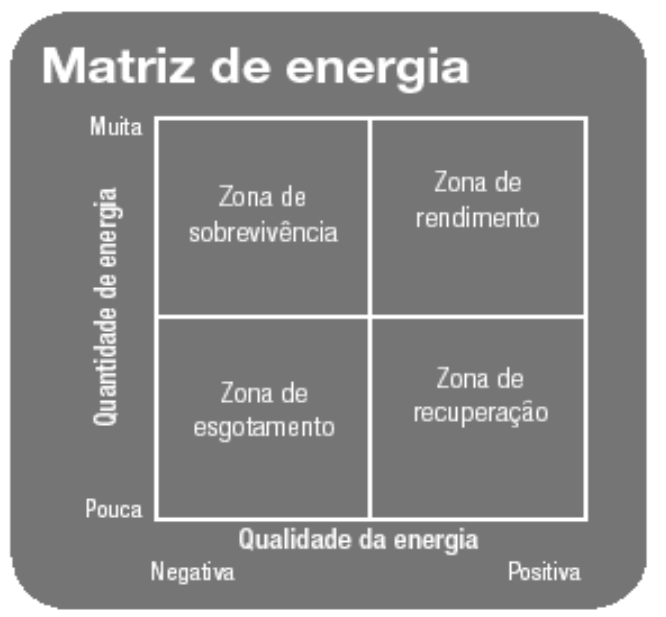

Fonte: Schwartz $(2007$, p. 3)

Segundo Schwartz (2007), quando uma pessoa consegue colocar em prática todo seu potencial, ela está entusiasmada, confiante, satisfeita, alegre e produtiva. Esses sentimentos descrevem a "zona de rendimento"; contudo, afirma Schwartz (2007), que poucas pessoas se mantêm nela a maior parte to tempo. Para ele as pessoas costumam se localizar na "zona de sobrevivência" onde mesmo com sensações de irritação e frustração, realizam o trabalho.

A permanência na "zona de sobrevivência" por muito tempo consumirá grande parte da energia e acabará levando a pessoa à "zona de esgotamento", na qual será 
muito difícil trabalhar. O último quadrante, a "zona de recuperação" está associada aos momentos de relaxamento que são poucos durante o trabalho. Assim se faz necessário alternar ciclos de gasto de energias com outros de renovação, como pequenas pausas durante o trabalho e as férias (SCHWARTZ, 2007).

Para Montanari e Pilatti (2010), o desempenho das pessoas trabalhando coletivamente é fundamental nos processos de criação do conhecimento, e trás influencias significativas na performance da equipe. Robbins (1999), por sua vez, propõe a utilização dos conhecimentos dos grupos de trabalho para criar equipes eficazes e relaciona alguns fatores como fundamentais ao bom desempenho das equipes. São eles:

a) Tamanho da equipe: a equipe não deve ter mais de 12 pessoas, pois dificulta a interação construtiva, a obtenção de consenso e o desenvolvimento da coesão, comprometimento e responsabilidade necessários para o alto desempenho;

b) Habilidades: a equipe precisa ser composta por pessoas que possuam técnica, capacidade para solucionar problemas e tomar decisões, habilidades interpessoais para ouvir, fornecer retorno e resolver conflitos;

c) Diversidade: apresenta nove possíveis papéis de equipe e propõe que para a equipe ser bem sucedida é necessário ter pessoas atuando em todos estes papéis. Os papéis chave na equipe são: conector, criador, promotor, assessor, organizador, produtor, controlador, mantenedor e conselheiro;

d) Compromisso: objetivo comum é a visão da equipe, que oferece direção, energia e comprometimento;

e) Metas: o propósito comum deve ser traduzido em metas mensuráveis e realistas. Essas metas dão energia, facilitam a comunicação e auxiliam na manutenção do foco em resultados;

f) Liderança e estruturação: os integrantes da equipe devem concordar sobre a distribuição das tarefas e assegurar uma divisão equilibrada da carga de trabalho; 
g) Vadiagem social e responsabilidade: tornando os membros da equipe responsáveis individualmente e coletivamente pelo propósito, metas e abordagem é possível minimizar a tendência à acomodação;

h) Avaliação de desempenho apropriada e sistemas de recompensa: além de avaliar e recompensar funcionários por suas contribuições individuais é preciso reforçar o empenho e comprometimento da equipe, através de avaliações baseadas no grupo, divisão de lucro e divisão de ganho;

i) Desenvolvimento de alto nível de confiança mútua: a confiança é característica de grupos de alto desempenho, ou seja, seus integrantes acreditam na integridade, caráter e capacidade de cada um.

O desempenho das equipes no ambiente produtivo é abordada por Montanari et al. (2011) que relacionam a perfomance dos grupos a maturidade das mesmas. Nas equipes estudadas pelos autores, observou-se que dentro de uma sequência evolutiva de funcionamento, as equipes aumentarem a maturidade e tendem a influenciar positivamente o seu desempenho no ambiente produtivo em que estão inseridas.

Nota-se que a performance das equipes, discutidas anteriormente por Bejarano (2006a), Bejarano et al. (2005b), Chang (1999), Schwartz (2007), Robbins (1999) e Montanari et al. (2011), divergem creditando o "bom" desempenho a fatores externos e internos. Constituir equipes para alcançar elevados índices de desempenho é tarefa complexa. Em linhas gerais, o desempenho das equipes está relacionado a inúmeros fatores que são interdependentes e dependentes dos estilos de trabalho dos membros que as compõem.

Há uma série de fatores presentes na coletividade laboral que atuam na performance das equipes no ambiente produtivo. Alguns fatores são citados como indispensáveis a melhor performance da equipe e continuam sendo observados ao longo dos anos por alguns autores - Goldbarg (1995), Parker (1995), Chang (1999), Katzenbach e Smith (2001), Aleixo (2003), Bejarano (2006a) e Montanari (2008).

O primeiro item diz respeito às reuniões das equipes. "Há várias crenças que depreciam o enfoque de equipe na empresa". Para algumas empresas as equipes não produzem melhor do que indivíduos bem capacitados e motivados e "perdem muito tempo em reuniões estéreis, em discussões irrelevantes e em sessões de queixas e lamentações" (MOSCOVICI 2003, p.21). No entanto, no atual território 
empresarial, as reuniões passam a ser muito importante ao processo de toma de decisões, pois as constantes mudanças e transformações requerem frequentes ajustes às organizações.

Para as equipes, as reuniões são fundamentais, pois coordenam e dão suporte às ações e mudanças. Uma reunião rápida e eficiente não é o objetivo principal; o desejado é o entusiasmo, a criatividade e participação de todos no processo de solução de problemas em debates abertos (GOLDBARG, 1995). Na visão de Aleixo (2003), sem reuniões as equipes não sobrevivem, pois são nessas ocasiões que os conflitos e os problemas de comunicação aparecem. São ocasiões também em que se oportunizam a troca de informações, ampliando a comunicação e consequentemente, 0 fortalecimento do comprometimento para desenvolver habilidades e preservar a experiência adquirida.

Um segundo item a considerar é a definição de metas e objetivos para a equipe. Bejarano (2006a) menciona o fato de a empresa identificar a necessidade estratégica do uso de equipes, bem como apoiar sua formação e implantar ações condizentes com objetivos e metas definidos. O sucesso das equipes está associado com a definição objetiva e clara das missões e metas. As Metas comuns levam ao compromisso e o envolvimento de todos nos objetivos da equipe (CHANG, 1999). Segundo Parker (1995, p. 79) "todas as equipes precisam ter uma missão e um conjunto de metas claras que todos os componentes da equipe apóiem". Goldbarg (1995) acrescenta relatando que as metas devem ser coletivas, claras, desafiadoras e alcançáveis.

Para avaliar o desempenho de equipes Chang (1999) elaborou um questionário denominado Avaliação de uma Equipe de Sucesso que apresenta 12 questões. O resultado numérico - oriundo das notas recebidas pelos membros das equipes - corresponde a uma interpretação elaborada pelo autor. Tanto o questionário quanto a interpretação serão utilizados na produção deste artigo não considerando se correspondem a fatores externos ou internos.

No contexto das equipes de sucesso de Chang (1999) e das equipes eficazes de Robbins (1999), é evidente que algumas características não dependem do estilo com que cada um trabalha em grupo, como por exemplo: o tamanho da equipe ou o estabelecimento de responsabilidades. Contudo, nota-se que alguns fatores 
expostos anteriormente - Bejarano et al. (2005b) e Schwartz (2007) - estão intimamente ligados ao estilo de trabalho em grupo e ao desempenho da equipe.

\section{METODOLOGIA DA PESQUISA}

Para obtenção de conhecimento científico se faz necessário conhecer as construções mentais que possibilitem alcançar os objetivos almejados. No idear de Gil (1999, p. 27), isso significa a determinação do método que "é o caminho para se chegar a determinado fim". Os procedimentos prescritos por Yin (2001), adaptados ao caso em exame, foram seguidos por se tratar de um método a ser utilizado em uma investigação empírica de um fenômeno dentro de seu contexto da vida real. Em termos práticos, observaram-se as seguintes etapas: a) revisão bibliográfica; b) elaboração de entrevista semi-estruturada composta de questões abertas e com roteiro para a sua condução; c) entrevista; d) observação não participante; e) definição da população; f) aplicação dos instrumentos de Parker (1994) para apurar o estilo de trabalho em grupo dos membros das equipes e de Chang (1999) para apurar o desempenho das equipes; g) análise dos dados e resultados.

Inicialmente buscou-se a construção do marco teórico referencial. A revisão bibliográfica procurou contemplar bibliografias pertinentes ao estilo de trabalho em grupo e os elementos associados ao desempenho de equipes.

Em seguida, uma entrevista semi-estruturada foi aplicada a um gerente da empresa. O procedimento teve caráter exploratório e buscou conhecer as equipes e a empresa em estudo. Para melhorar a interpretação das respostas e dos registros na entrevista, utilizou-se, com a autorização do entrevistado, um gravador. A gravação foi transcrita literalmente para facilitar a análise. Por outro lado, juntamente com a aplicação dos instrumentos, as observações de caráter não participante buscaram registrar elementos de interesse para o cumprimento dos objetivos desta pesquisa.

Os instrumentos foram aplicados aos membros das equipes procurando explicar todas as questões dos questionários aos respondentes para que eles tivessem entendimento claro dos aspectos perguntados. Juntamente com a aplicação dos instrumentos, as observações de caráter não participante buscaram registrar elementos de interesse para o cumprimento dos objetivos desta pesquisa. 
O primeiro instrumento aplicado foi o questionário proposto por Parker (1994). O questionário é composto por 18 questões nas quais os respondentes distribuíram em cada questão notas até 4 para a situação que mais se aplicasse e até 1 para a que menos se aplicasse. O segundo instrumento foi o questionário sugerido por Chang (1999). A avaliação é composta de doze questões que recebem notas numa escala de 1 a 7 . Em relação a cada característica, a nota 7 significa que a equipe é excepcional e a nota 1 , que é deficiente.

Para o instrumento de Parker (1994), as pontuações, atribuídas pelos membros das equipes, foram transferidas para um quadro proposto pelo autor e em seguida apurado o estilo de trabalho em grupo. Para o cálculo dos pontos da equipe, conforme avaliação de Chang (1999), somou-se os pontos atribuídos individualmente a cada característica do questionário, fez-se a média dividindo os pontos pelo número de questionários respondidos e ao final fez-se a soma das notas que originaram a pontuação da equipe. Os instrumentos contendo as instruções para os respondentes, assim como as questões e as orientações dos autores para análise estão disponíveis, respectivamente, nos anexos I e II.

A população foi composta de um universo de 77 membros de equipes da empresa em estudo. O número de respondentes foi de 75 membros. Dois membros de equipe foram descartados, pois estavam participando da primeira reunião em suas equipes e entendeu-se que eles não tinham experiência prática suficiente para responder aos questionários. Os membros das equipes responderam aos questionários identificando somente a equipe a que pertenciam. Em seguida, os questionários foram depositados pelos próprios respondentes em urnas a fim de assegurar sigilo sobre suas opiniões e, também, estabelecer um clima de confiança e empatia (TRIVIÑOS, 1987).

Por fim, procurou-se analisar os resultados fazendo a triangulação dos dados obtidos nas entrevistas, nos questionários, no instrumento e nas observações não participantes. Segundo Yin (2001, p. 121), "várias fontes de evidências fornecem essencialmente várias avaliações do mesmo fenômeno". Tal procedimento também teve a intenção de aumentar a compreensão para avaliar a influência do estilo de trabalhar em grupo no desempenho das equipes em estudo. 


\section{RESULTADOS E DISCUSSÕES}

As experiências pessoais e profissionais criam ou determinam um estilo nas pessoas que, no trabalho em equipe ou em outro qualquer, trabalham num continuum interagindo com o ambiente que estão inseridas. Formar grupos ou equipes de trabalho com o equilíbrio ideal de personalidades ou estilos torna-se fundamental diante da crescente utilização da gestão baseada em equipes, retratada por inúmeros autores: Gilley et al. (2010), Claver-Cortés et al. (2007), Bejarano (2006a), Drucker (2001) e Sacomano e Escrivão Filho (2000).

As observações não participantes nas reuniões das equipes e a entrevista exploratória permitiram mapear as equipes e suas características:

a) Estrutura das equipes: um líder, escolhido de forma democrática pelos membros da equipe; um facilitador determinado pela empresa para auxiliar nas reuniões;

b) Missão da Equipe: cada equipe tem uma missão que foi estabelecida pelos membros da equipe;

c) Regras: cada equipe tem regras de comportamento entre os membros durante as reuniões, tais como: não chegar atrasado, participar até o seu término, contribuição nas discussões, ausência de conversas paralelas, seja sobre o assunto ou fora dele, a liberdade de expressão, sem censuras e somente uma pessoa fala de cada vez, e

d) Reuniões: o facilitador criou uma agenda de reuniões e definiu junto aos membros das equipes regras para as reuniões, como: uso de pauta e registro em ata das questões levantadas e decisões tomadas.

Observa-se na estruturação das equipes dois itens, que segundo a percepção de alguns autores - Goldbarg (1995), Parker (1995), Chang (1999), Katzenbach e Smith (2001), Aleixo (2003) e Bejarano (2006a) - são imprescindíveis ao seu desempenho: missão e reuniões.

O estabelecimento de uma missão para as equipes, segundo o idear de Parker (1995), é uma medida que auxilia no desempenho da equipe, principalmente quando há o apoio dos componentes. Na empresa em estudo, a maneira como ela envolveu os membros das equipes na criação de uma missão pode auxiliar muito criando um ambiente propício para desenvolvimento de um senso de 
comprometimento entre os membros, o que na visão de Solansky (2011) contribui muito para maximizar a performance das equipes através da identificação de seus integrantes com a equipe e seus objetivos.

A agenda de reuniões criada para as equipes também representa um elemento de fundamental importância ao desempenho das equipes. $\mathrm{Na}$ visão de Aleixo (2003) e Goldbarg (1995), as reuniões constituem um ambiente favorável que oportuniza a troca de informações e auxiliam como suporte necessário à performance da equipe.

Tomando como base as respostas do entrevistado em relação aos processos de recrutamento e seleção de candidatos observa-se que a empresa em estudo os recruta e os seleciona mediante testes que avaliam as habilidades profissionais. Os candidatos contratados são inseridos nas equipes de acordo com as suas habilidades. Em linhas gerais, as equipes são compostas na empresa em estudo tendo como critério de seleção um balanceamento entre os membros que já possuem algumas habilidades necessárias e os que precisavam desenvolvê-las.

A atual política de formação de equipes na empresa em estudo vem ao encontro com o que Aleixo (2003) aborda. Esta autora defende a ideia de fazer um balanceamento entre os membros com alguma habilidade com os que precisam desenvolvê-las. Armstrong (1997), Bejarano et al. (2005b) e Davies e Kanaki (2006), inferem que um processo de seleção mais amplo, contemplando a busca de mais características dos candidatos, pode colaborar no sentido de possibilitar as organizações no desenho da equipe ideal. Em linhas gerais, contribui muito para o desempenho da equipe a tentativa de equilibrar personalidades para melhorar a performance.

Para avaliar a influência do estilo de trabalho em grupo no desempenho das sete equipes na empresa em estudo, 75 membros das equipes em estudo responderam ao questionário proposto por Parker (1994). A Tabela 1 quantifica a predominância de estilos entre os membros das equipes. 
Tabela 1 - Estilo de trabalhar em grupo

Contribuinte Colaborador Comunicador Desafiador

\begin{tabular}{lllll} 
& \multicolumn{5}{c}{ Número de vezes que o estilo predominou } \\
\cline { 2 - 5 } Equipe 1 & 7 & 4 & 3 & 0 \\
Equipe 2 & 9 & 2 & 5 & 1 \\
Equipe 3 & 5 & 6 & 4 & 3 \\
Equipe 4 & 4 & 5 & 3 & 5 \\
Equipe 5 & 5 & 5 & 4 & 1 \\
Equipe 6 & 4 & 4 & 3 & 5 \\
Equipe 7 & 7 & 1 & 1 & 2 \\
\hline
\end{tabular}

Fonte: os autores

Observa-se que no geral o estilo predominante entre os membros das equipes foi o contribuinte, em seguida colaborador e comunicador e por último o estilo desafiador. Segundo Parker (1994), os membros de uma equipe podem ter diferentes estilos de trabalho, porém um ou dois estilos acabam prevalecendo e definem um conjunto de comportamentos presentes na equipe.

Os resultados das equipes 3,4 e 6 merecem atenção no que diz respeito à predominância dos estilos. Nessas equipes os estilos apareceram de maneira mais uniforme, não apresentando tanta disparidade quanto nas equipes 1, 2, 5 e 7, que apresentam mais membros com estilo contribuinte e menos com o desafiador.

Esses resultados, segundo Robbins (1999), Katzenbach e Smith (2001), Moscovici (2003) e Bejarano (2006a), não são os ideais, pois equipes eficazes necessitam de habilidades complementares entre os membros, como enfatizou Higgs (2005) apontando a influência positiva da diversidade entre os membros de uma equipe.

$\mathrm{Na}$ visão de Bejarano (2005b), o equilíbrio de funções e personalidades é fundamental para que a equipe possa atingir seu potencial. A disparidade da predominância de estilos equipes 1, 2, 5 e 7 reflete, também, a política de recrutamento e seleção utilizada pela empresa que, segundo o entrevistado, visa somente conhecer algumas habilidades profissionais dos candidatos.

Para mensuração do desempenho das equipes em estudo, os seus membros responderam ao questionário de Chang (1999), e os resultados são mostrados na Tabela 2 abaixo: 
Tabela 2 - Desempenho das equipes

\begin{tabular}{|c|c|c|c|c|c|c|c|}
\hline \multirow[t]{2}{*}{ CARACTERÍSTICAS } & 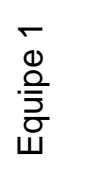 & 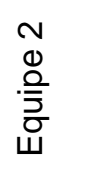 & 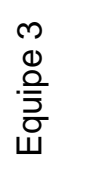 & 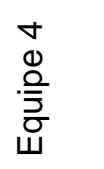 & 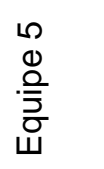 & $\begin{array}{l}0 \\
\mathbb{D} \\
. \bar{\Xi} \\
\overline{\tilde{J}}\end{array}$ & $\begin{array}{l}\hat{\emptyset} \\
\stackrel{0}{\bar{\Xi}} \\
\text { ত্ّ }\end{array}$ \\
\hline & \multicolumn{7}{|c|}{$\mathrm{NOTAS}$} \\
\hline 1 - Deixa sua missão e suas metas claras & 6,00 & 5,45 & 5,18 & 5,09 & 6,18 & 5,36 & 5,90 \\
\hline 2 - Funciona de maneira criativa & 6,20 & 6,00 & 5,00 & 5,27 & 5,27 & 5,54 & 5,90 \\
\hline 3 -Concentra-se nos resultados & 6,00 & 5,90 & 5,54 & 5,81 & 5,90 & 5,00 & 6,36 \\
\hline 4-Esclarece funções e responsabilidades & 6,80 & 5,54 & 6,00 & 5,72 & 6,36 & 5,18 & 6,54 \\
\hline 5 - É bem organizada & 5,30 & 5,54 & 4,90 & 5,09 & 5,36 & 5,09 & 5,72 \\
\hline 6- Baseia-se nas potencialidades individuais & 5,80 & 5,09 & 5,18 & 5,18 & 5,72 & 5,00 & 5,72 \\
\hline $\begin{array}{l}7 \text { - Apoia a liderança e cada um dos } \\
\text { membros }\end{array}$ & 6,30 & 6,27 & 4,09 & 4,81 & 6,63 & 4,90 & 6,45 \\
\hline 8 - Desenvolve um ambiente de equipe & 5,50 & 6,81 & 4,63 & 4,81 & 5,90 & 4,54 & 6,45 \\
\hline 9 - Soluciona as discordâncias & 6,00 & 6,00 & 5,81 & 5,63 & 6,00 & 5,27 & 5,63 \\
\hline 10 - Comunica-se francamente & 6,00 & 5,45 & 5,00 & 5,18 & 6,09 & 5,54 & 6,09 \\
\hline 11-Toma decisões objetivas & 6,10 & 6,00 & 5,36 & 5,09 & 5,45 & 5,27 & 6,00 \\
\hline 12 - Avalia sua própria eficiência & 6,10 & 5,72 & 5,63 & 5,63 & 5,72 & 5,18 & 6,27 \\
\hline PONTUAÇÃO (somatório das notas) & 72,10 & 70,81 & 63,18 & 63,36 & 70,63 & 61,90 & 73,09 \\
\hline
\end{tabular}

Fonte: os autores

Segundo Chang (1999) o desempenho das equipes 1, 2, 5 e 7 é caracterizado como "nada mal, essas equipes estão em boa forma, mas ainda é possível melhorar". Já as equipes 3, 4 e 6 apresentam um desempenho deficiente. Essas equipes "apresentam problemas sérios e terão que concentrar os esforços para melhorar as características" apresentadas na Tabela 2 e que tiveram baixa pontuação.

Um fator interessante a considerar nesses resultados é a predominância dos estilos nas equipes e o seu desempenho. Os resultados do questionário que avaliou o desempenho das equipes - Avaliação de uma Equipe de Sucesso proposto por Chang (1999) - evidenciaram que as equipes 3, 4 e 6 tiveram a melhor distribuição dos diferentes estilos, mas em contrapartida apresentaram o menor desempenho comparadas as demais equipes.

Esses resultados são divergentes com o que Bejarano (2006a), Higgs (2005) e Robbins (1999) apresentam sobre a necessidade de habilidades complementares para formação de equipes eficazes. Na visão de Thomaz e Kovaleski (2006) e Montanari e Pilatti (2009), há estilos de trabalho em grupo, segundo a classificação de Parker (1994), que são mais favoráveis para que ocorra o compartilhamento do conhecimento. Neste contexto pode-se inferir segundo Parker (1994), que todos os estilos têm sua participação no trabalho em equipe em um determinado momento. A 
familiaridade entre os membros da mesma equipe, discutida por Costa (2003), está contribuindo para um melhor desempenho nas equipes com predominância de um estilo (1, 2, 5 e 7$)$.

Observa-se que a presença do estilo desafiador - citado por Parker (1994) como um participante que questiona os objetivos e tem predisposição para discordar - foi o que mais predominou nas equipes que obtiveram o menor desempenho (equipes 3, 4 e 6). Na Tabela 2 essa influência é também percebida nos itens 7 e 8 dessas equipes, pois as notas indicam respectivamente problemas de apoio à liderança e aos membros da equipes e problemas no ambiente das equipes em estudo.

Outra influência pode ser notada nas equipes que tiveram melhor desempenho (equipes 1, 2, 5 e 7), nas quais o estilo que mais predominou foi 0 contribuinte. Este estilo, segundo Parker (1994), é o estilo de um participante orientado para a execução de tarefas, e que é descrito como alguém confiável, responsável, autoritário, competente, organizado e que algumas vezes se enrola com detalhes.

Dentre os estilos citados por Parker (1994), o estilo contribuinte é o único a ser descrito com a característica: responsável. Esta característica pode estar associada à maturidade do liderado citada por Hersey e Blanchard (1986), pois segundo esses autores a maturidade é a capacidade da pessoa em assumir responsabilidades do seu comportamento.

O estilo colaborador, descrito por Parker (1994) como um participante orientado para o objetivo e dá a maior importância para as metas, também traz influências nas equipes em estudo. Estas são percebidas nas equipes 3, 4 e 6 que tiveram maior predominância deste estilo e o menor desempenho.

A influência do estilo comunicador - segundo Parker (1994) é um participante capaz de ouvir bem e de facilitar a participação alheia - é percebida nas equipes em estudo nos resultados da Tabela 2. Os itens 4 (esclarece funções e responsabilidade), 9 (soluciona discordâncias) e o 10 (comunica-se francamente) apontam as melhores notas nesses itens para as equipes com melhor desempenho.

Verificando-se os fatores de uma equipe eficaz proposto por Robbins (1999), a partir das observações não participantes e da entrevista na empresa, nota-se que todas as equipes contemplam alguns fatores como: tamanho da equipe e definição 
de metas. Entretanto, alguns fatores merecem a atenção em relação aos resultados expressos na Tabela 2. O primeiro deles é sobre as metas: segundo o entrevistado e o relatório das observações não participantes, todas as equipes estabeleceram uma missão para a equipe. Considerando que as equipes eficazes apresentam diversidade de estilos, percebe-se na Tabela 2 que a característica 1 (Deixa sua missão e suas metas claras) tem as notas mais baixas nas equipes 3, 4 e 6 e são as equipes com a melhor distribuição de estilos.

O segundo fator é sobre as habilidades dos membros. Robbins (1999) e Hersey e Blanchard (1986) citam que as equipes precisam ser compostas por pessoas com habilidades para solucionar problemas e tomar decisões. Nota-se na Tabela 2 que as características 9 (soluciona discordâncias) e 11 (toma decisões objetivas) das equipes 3, 4 e 6 - equipes com melhor distribuição de estilos apresentam as notas mais baixas.

A influência do estilo de trabalho em grupo é clara e evidencia a necessidade de avaliar todos os fatores na construção ou reestruturação de equipes, independentes de externos ou internos. No presente caso, observa-se que não há uma personalidade ou um estilo de trabalho em grupo que determinará o desempenho da equipe. $O$ desempenho das equipes em exame está associado à familiaridade entre os membros discutida por Costa (2003) e Montanari (2008).

\section{CONCLUSÕES}

Os resultados deste estudo permitiram avaliar a influência do estilo de trabalho em grupo no desempenho das equipes e identificar duas matrizes de resultados na empresa em estudo. A primeira permeada por uma distribuição mais uniforme dos estilos entre os membros das equipes 3,4 e 6 , porém com menor desempenho das equipes. $\mathrm{E}$ a segunda matriz de resultados (equipes 1, 2, 5 e 7) com uma predominância de estilos do tipo contribuinte e um maior desempenho das equipes.

Esses resultados são divergentes dos encontrados nos estudos de Bejarano (2006a), Higgs (2005) e Robbins (1999), os quais preconizam a necessidade de membros com habilidades complementares. Entretanto, outros fatores influenciaram a primeira matriz de resultados encontrada, pois mesmo apresentando a variedade 
de estilos necessária para uma equipe eficaz, as equipes 3,4 e 6, apresentaram problemas sérios como: falta de clareza nas missões e metas, falta de apoio à liderança e necessidade de solucionar discordâncias e tomar decisões objetivas.

Pode-se inferir, no presente caso, que a predominância dos diferentes estilos de trabalho em grupo nas equipes em estudo influenciou seu desempenho. $O$ estilo contribuinte predominou nas equipes com melhor desempenho. $O$ estilo colaborador e desafiador predominaram nas equipes com menor desempenho. E o estilo comunicador esteve permeou todas as equipes. Apesar das influências de cada estilo, se faz necessário considerar outros fatores: externos e internos às equipes; gastos de energia dos membros das equipes - discutidos por Schwartz (2007), e a maturidade dos membros das equipes, abordada por Hersey e Blanchard (1986).

São fatores que auxiliam a selecionar membros com alta maturidade e com capacidade e disposição para assumir responsabilidades e melhorar o desempenho das equipes através do equilíbrio da capacidade e energia para desenvolvimento das atividades nas equipes.

Com relação aos resultados discutidos, pode-se utilizar a analogia feita por Drucker (2001), quando compara o trabalho em equipe a um conjunto de jazz: os membros devem "cobrir" seus companheiros de equipe, ajustando-se quando necessário, pois, embora exercendo funções diferenciadas, a perfeita sintonia somente é percebida se todos os integrantes estiverem harmonizados entre si. A sintonia no caso em questão é evidenciada na predominância de um estilo de trabalho em grupo presente nas equipes com melhor desempenho que auxilia nas relações entre os membros e contribui significativamente na performance da equipe.

\section{REFERÊNCIAS}

ALEIXO, A. I. S. Procedimentos para implantar equipes. 2003. 111f. Dissertação (Mestrado em Engenharia da Produção) - Programa de Pós-Graduação em Engenharia de Produção, Universidade Federal de Santa Catarina. Florianópolis, 2003.

ARMSTRONG, A. Using assessment centers to select team leaders. Asia Pacific Journal of Human Resources, p. 35-67,1997.

BEJARANO, V. C. Elementos essenciais à implementação de equipes: um estudo de caso da indústria de papel. 2006. 115f. Dissertação (Mestrado em 
Engenharia da Produção) - Programa de Pós-Graduação em Engenharia de Produção, UTFPR, Ponta Grossa, 2006a.

BEJARANO, V. C.; PILATTI, L. A. Elementos externos essenciais à implementação de equipes: estudo de caso. Revista de Administração da Universidade de São Paulo. São Paulo, v. 43, n. 1, p. 17-29, jan./mar. 2008.

BEJARANO, V. C. et al. Como formar equipes com equilíbrio ideal de personalidades e perfis pessoais: a teoria e as ferramentas de Meredith Belbin. In: CONGRESSO BRASILEIRO DE ENSINO DE ENGENHARIA, 33, 2005, Campina Grande. Anais ... Campina Grande: Universidade Federal de Campina GrandeUFCG, 2005b. p. 1-12.

BEJARANO, V. C. et al. Equipes e Comunidades de Prática como Estruturas Complementares na Gestão do Conhecimento Organizacional. In: Encontro Nac de Eng de Produção, XXV, 2005, Porto Alegre. Anais ... Porto Alegre: ABEPRO, 2005a. p. 4851-4856.

BEJARANO, V. C. et al. Equipes virtuais: um estudo de caso na indústria têxtil norteamericana. Revista Produção. São Paulo, v.16, n. 1, p. 1-13, abr. 2006.

COSTA, A. C. Work Team Trust and Effectiveness. Personnel Review, v. 32, n. 5, p. 605-622, 2003.

CLAVER-CORTÉS, E. et al. Organizational structure features supporting knowledge management processes. Journal of Knowledge Management. v. 1, n. 4. p. 45-57. 2007.

CHANG, R. Y. Construindo uma equipe de sucesso. São Paulo: Futura, 1999.

DAVIES, M. F.; KANAKI, E. Interpersonal characteristics associated with different team roles in work groups. Journal of Managerial Psychology, v. 21, n. 7, p.638650, 2006.

DRUCKER, P. F. Administrando em tempos de grandes mudanças. São Paulo: Pioneira Thomsom Learning, 2001.

GIL, A. C. Métodos e técnicas de pesquisa social. São Paulo: Atlas, 1999.

GILLEY, A. The Competencies Used by Effective Managers to Build Teams: na empirical study. Advances in Developing Human Resources, v. 12, n. 1, p. 29-45. 2010.

GOLDBARG, M. A. Times: ferramenta eficaz para a qualidade total. São Paulo: Makron, 1995.

HIGGS, M. Influence of team composition and task complexity on team performance. Team Performance Management, v. 11, n. 7/8, p. 227-250, 2005. 
FISHER, S. G. et al. Team or group?: managers' perceptions of the differences. Journal of Managerial Psychology. v. 12, n. 4, p. 232-242, 1997.

HERSEY, P.; BLANCHARD, K. H. Psicologia para administradores: as teorias e as técnicas da liderança situacional. São Paulo: EPU, 1986.

KARAKOWSKY, L. et al. Perceptions of team performance: the impact of group composition and task-based cues. Journal of Managerial Psychology, v. 19, n. 5, p. 506-525, 2004.

KATZENBACH, J. A Disciplina das equipes. HSM-Management. São Paulo, n. 17, p. 56-60, nov./dez. 1999.

KATZENBACH, J. R.; SMITH, D. K. Equipes de alta performance: conceitos, princípios e técnicas para potencializar o desempenho das equipes. Rio de Janeiro: Campus, 2001.

MONTANARI, R. L. Os Homens e as equipes de trabalho no ambiente produtivo. 2008. 187f. Dissertação (Mestrado em Engenharia da Produção) - Programa de Pós-Graduação em Engenharia de Produção, UTFPR, Ponta Grossa, 2008.

MONTANARI, R. L. et al. A maturidade e o desempenho das equipes no ambiente produtivo. Gestão \& Produção. São Carlos, v. 18, n. 2, p. 1-12, 2011.

MONTANARI, R. L.; PILATTI, L. A. A Influência do estilo de trabalhar em grupos nos processos de construção do conhecimento organizacional. In: ENCONTRO NACIONAL DE ENGENHARIA DE PRODUÇÃ̃O, 29, 2009, Salvador. Anais ... Salvador: ABEPRO, 2009. p. 1-14.

MONTANARI, R. L.; PILATTI, L. A. La madurez del trabajo em equipo y lós procesos de construcción del conocimiento organizacional y de la innovación tecnológica.

Espacios, v. 31, n. 3, p.47-48, 2010.

MOSCOVICI, F. Equipes dão certo: a multiplicação do talento humano. 8. ed. Rio de Janeiro: José Olympio, 2003.

PARKER, G. M. Team players and teamwork. São Paulo: Pioneira, 1994.

PARKER, G. M. O Poder das equipes. Rio de Janeiro: Campus, 1995.

ROBBINS, H.; FINLEY, M. Por que as equipes não funcionam?. Rio de Janeiro: Campus, 1997.

ROBBINS, S. P. Comportamento organizacional. 8. ed. Rio de Janeiro: LTC, 1999.

ROBBINS, S. P. Administração: mudanças e perspectivas. São Paulo: Saraiva, 2001. 
SACOMANO N. M.; ESCRIVAO Filho, E. Estrutura organizacional e equipes de trabalho: estudo da mudança organizacional em quatro grandes empresas industriais. Gestão \& Produção, São Carlos, Ago, v. 7, n. 2, p.136-145, 2000.

SOLANSKY, S. Team Identification: a determining factor of performance. Journal of Managerial Psychology. v. 26. n. 3. p.247-258, 2011.

SCHWARTZ, T. A Energia dá a Partida. HSM-Management. São Paulo, n. 62, p.1-4, maio/jun. 2007.

SZEZERBICKI, A. S. et al. Gestão do conhecimento em equipes de alta performance: o caso do clube Atlético Paranaense. Revista Produção Online. Florianópolis, v. 6, n. 2, p. 1-26, ago. 2006.

TOMAZ, M. S.; KOVALESKI, J. L. Aspectos sobre compartilhamento de conhecimento tácito e estilos de trabalho em equipe: um estudo de caso em uma empresa de energia elétrica. In: OLIVEIRA, M. R. et al. [orgs.] Gestão estratégica para a competitividade. Ponta Grossa: Editora UEPG, 2006. Cap. Gestão do Conhecimento e Inovação, p. 173-184.

TRIVINOS, A. Introdução à pesquisa em ciências sociais. São Paulo: Atlas, 1987.

YIN, R. K. Estudo de caso: planejamento e métodos. 2. ed. Porto Alegre: Bookman, 2001.

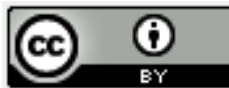

Artigo recebido em 24/08/2010 e aceito para publicação em 19/06/2012. 
Anexo I - Instrumento de Parker (1994)

Instruções para o preenchimento:

a) Responda cada questão sinceramente, de acordo com o que você pensa a respeito de seu desempenho atual como membro de equipe e não com o que você acha que era ou gostaria de ser.

b) Por ser um levantamento, não existem respostas certas ou erradas.

c) Cada uma das 18 questões tem quatro alternativas. Coloque em ordem as alternativas conforme você julgue que elas se aplicam a você.

ATENÇÃO: Dê o número 4 à alternativa que mais se aplica a você e continue até 1, que deverá ser dado à alternativa que menos se aplica a você.

Exemplo:

Como membro de equipe, normalmente eu me preocupo mais com:

$\underline{3}$ a. observar padrões éticos elevados.

$\frac{3}{4}$ b. atingir nossas metas.

$\overline{4}$ c. cumprir minhas responsabilidades pessoais.

2 d. saber se estamos trabalhando bem juntos.

d) Transfira as respostas para o quadro de resultados.

e) Efetue as somas indicadas.

\section{Questões:}

1. Durante as reuniões de equipe, normalmente eu:

a. forneço informações e dados técnicos aos colegas.

b. mantenho o grupo orientado para a missão e as metas.

c. procuro fazer todo mundo participar da discussão.

d. levanto questões sobre as metas e os métodos do grupo.

2. Quando converso com o líder da equipe, eu:

a. sugiro que o trabalho concentre-se nos objetivos.

b. tento ajudá-lo a manter uma atmosfera positiva.

c. estou disposto a discordar dele quando necessário.

d. ofereço conselhos com base em minha experiência.

3. Quando a situação fica tensa, eu:

a. uso humor e outras formas de reduzir a tensão.

b. costumo ser muito franco para dizer o que penso.

c. perco a paciência porque é necessário manter todos participando da discussão.

d. vou me queixar a gente de fora sobre os problemas que meu grupo enfrenta.

4. Quando surgem conflitos na equipe, normalmente eu:

a. insisto na discussão honesta das diferenças.

b. mostro as razões pelas quais um lado ou outro está correto.

c. encaro as diferenças como sinal de uma mudança na direção do grupo.

d. tento desfazer a tensão com algum comentário de apoio ou alguma brincadeira.

5. Outros membros da equipe normalmente me veem como:

a. prático.

b. flexível.

c. incentivador.

d. franco.

6. De vez em quando, eu:

a. fico obcecado com os resultados.

b. ando meio desligado.

c. sou muito autoconfiante.

d. enxergo apenas a situação imediata.

7. Quando as coisas começam a dar errado no grupo, normalmente eu:

a. insisto que é mais necessário ouvir, dar feedback e participar.

Revista Produção Online, Florianópolis, SC, v.12, n. 3, p. 558-584, jul./set. 2012. 
b. insisto que é necessário discutir os problemas com franqueza.

c. trabalho duro para conseguir e fornecer mais informações de melhor qualidade.

d. sugiro que façamos uma revisão de nossos objetivos básicos.

8. Para mim, uma coisa arriscada é:

a. questionar algum aspecto do trabalho do grupo.

b. pressionar o grupo para elevar seus padrões de desempenho.

c. desempenhar outro papel que não seja o meu.

d. dizer aos outros como eles estão se saindo.

9. De vez em quando, os outros me enxergam como:

a. um perfeccionista.

b. alguém que não gosta de modificar as metas ou objetivos.

c. alguém que não leva a sério o trabalho a ser feito.

d. um detalhista.

10. Acredito que a resolução de problemas do grupo exige:
a. cooperação de todos os participantes.
b. elevada capacidade de ouvir.
c. capacidade de fazer perguntas difíceis.
d. informações de alta qualidade.

11. Quando uma nova equipe está em formação, normalmente eu:

a. vou procurar e tentar conhecer os outros.

b. faço perguntas diretas sobre os métodos e metas.

c. quero saber o que se espera de mim.

d. procuro estabelecer qual é o objetivo básico.

12. De vez em quando, eu faço outras pessoas sentirem-se:

a. desonestas, por não conseguirem ser tão diretas como eu.

b. culpadas, por não atingirem meus padrões.

c. obtusas, por não conseguirem enxergar a longo prazo.

d. sem coração, por não se importarem com a maneira como as pessoas se relacionam.

13. Acredito que o papel do líder do grupo é:

a. garantir a solução eficaz dos problemas de trabalho.

b. ajudar o grupo a estabelecer objetivos de longo prazo e metas de curto prazo.

c. criar um clima participativo de tomada de decisão.

d. fazer a convergência de ideias distintas e desafiar as premissas.

14. Acredito que as decisões do grupo devem fundamentar-se:

a. na missão e nas metas do grupo.

b. no consenso entre os membros do grupo.

c. na avaliação franca e aberta dos assuntos.

d. no peso das evidências.

15. De vez em quando, eu:

a. acho que a atmosfera humana do grupo é um fim em si próprio.

b. banco o advogado do diabo com muita ênfase.

c. não consigo enxergar a importância da eficácia nos processos grupais.

d. exagero a importância dos assuntos estratégicos e minimizo a realização das tarefas de curto prazo

16. Já fui descrito como:

a. independente.

b. confiável.

c. imaginoso.

d. participativo.

Revista Produção Online, Florianópolis, SC, v.12, n. 3, p. 558-584, jul./set. 2012. 
17. Na maior parte do tempo, eu:

a. sou responsável e trabalho duro.

b. comprometido e flexível.

c. entusiasmado e alegre.

d. honesto e autêntico.

18. Nas minhas relações com os colegas de grupo, de vez em quando fico aborrecido porque eles:

a. não se preocupam em fazer a revisão dos objetivos e verificar o progresso.

b. não conseguem enxergar a importância de trabalhar bem juntos.

c. não fazem objeções às coisas das quais discordam.

d. não conseguem terminar seus compromissos dentro dos prazos.

Instruções para análise:

A ordem das letras muda para cada questão. Observe que na questão 1 , a ordem é a, b, c, d. Já na questão 2 a ordem é d, a, b, c. Portanto, CUIDADO NA TRANSCRIÇÃO! A soma total dos quatro estilos deve ser igual a 180.

\begin{tabular}{|c|c|c|c|c|}
\hline Questão & Contribuinte & Colaborador & Comunicador & Desafiador \\
\hline 1 & a. & b. & c. & d. \\
\hline 2 & d. & a. & b. & c. \\
\hline 3 & c. & d. & a. & b. \\
\hline 4. & b. & c. & d. & a. \\
\hline 5. & a. & b. & c. & d. \\
\hline 6. & d. & a. & b. & c. \\
\hline 7. & c. & d. & a. & b. \\
\hline 8. & b. & c. & d. & a. \\
\hline 9. & a. & b. & c. & d. \\
\hline 10. & d. & a. & b. & c. \\
\hline 11. & c. & d. & a. & b. \\
\hline 12. & b. & c. & d. & a. \\
\hline 13. & a. & b. & c. & d. \\
\hline 14. & d. & a. & b. & c. \\
\hline 15. & c. & d. & a. & b. \\
\hline 16. & b. & c. & d. & a. \\
\hline 17. & a. & b. & c. & d. \\
\hline 18. & d. & a. & b. & c. \\
\hline Totais por Es & & & & \\
\hline
\end{tabular}

Revista Produção Online, Florianópolis, SC, v.12, n. 3, p. 558-584, jul./set. 2012. 
Anexo II - Instrumento de Chang (1999)

Instruções para preenchimento:

a) Responda cada questão sinceramente e de acordo com o que você pensa a respeito de seu desempenho atual como membro de equipe e não com o que você acha que era ou gostaria de ser;

b) Assinale um $\mathrm{X}$ no número que melhor reflete a sua percepção.

Questões:

1 - Deixa sua missão e suas metas claras

1234567

2 - Funciona de maneira criativa

1234567

3 - Concentra-se nos Resultados

1234567

4 - Esclarece Funções e Responsabilidades

1234567

5 - É bem-organizada

1234567

6 - Baseia-se nas potencialidades individuais

1234567

7 - Apoia a liderança e cada um dos membros

1234567

8 - Desenvolve um ambiente de trabalho em equipe

1234567

9 - Soluciona as discordâncias

1234567

10 - Comunica-se francamente

1234567

11 - Toma decisões objetivas

1234567

12 - Avalia sua própria eficiência

1234567

Total de Pontos

\section{Instruções para análise:}

Faça a soma das pontuações atribuídas as questões de um único questionário e divida o resultado pelo número de perguntas do questionário para identificar o desempenho da equipe sob o ponto de vista de um único membro. A soma das notas individuais, dividida pelo número de membros da equipe, confere a pontuação à equipe.

a) Se o seu total foi de 75-84: Parabéns! A sua equipe atingiu ou está quase atingindo o desempenho ótimo. Manter a equipe nesse nível elevado deverá ser seu objetivo;

b) Se o seu total foi de 65-74: Nada mal! A sua equipe está em boa forma, mas ainda é possível melhorar;

c) Se o seu total foi de 55-64: A sua equipe tem problemas, alguns deles sérios. Para corrigi-los, a equipe terá de concentrar-se no aperfeiçoamento das características em que a pontuação é mais baixa;

d) Se o seu total foi de 54 ou menos: Os membros da sua equipe não estão atuando como deveriam. A sua equipe precisa trabalhar naqueles elementos básicos para 0 desenvolvimento. 